\title{
EFEKTIFITAS PENGGUNAAN AUDIO RECORDER GUIDED IMAGERY MUSIC (GIM) TERHADAP NYERI PADA PASIEN PASCA BEDAH LAPARATOMI DI RS. BLUD PROF DR DR H ALOE SABOE KOTA GORONTALO
}

\author{
Yusrin Aswad ${ }^{1}$, Paulus Pangalo 2 \\ ${ }^{1}$ Poltekes Kemenkes Gorontalo, Moodu, Kota Tim., Kota Gorontalo, Gorontalo 96135 \\ Email: yusrinaswad@gmail.com \\ ${ }^{2}$ Poltekes Kemenkes Gorontalo, Moodu, Kota Tim., Kota Gorontalo, Gorontalo 96135 \\ Email: pangalop@gmail.com
}

\begin{abstract}
ABSTRAK
Penelitian ini bertujuan untuk mengetahui efektifitas penggunaan audio recorder guided imagery music (gim) terhadap nyeri pada pasien pasca bedah laparatomi di rumah sakit blud prof $\mathrm{dr} \mathrm{dr}$ $\mathrm{h}$ aloe saboe kota gorontalo. Jenis penelitian ini adalah quasi experimen dengan desain "group pre and post test design with control group" pengukuran nyeri dilakukan sebelum dan sesudah intervensi. Populasi pada penelitian ini adalah semua pasien pasca bedah laparatomi di ruangan Bedah di rumah sakit RSAS. Pengambilan sampel disini dilakukan dengan cara Non Probobality Sampling dengan teknik Purposif sampling. Peneliti mengambil semua subjek sesuai criteria inklusi sampai jumlah subjek minimal terpenuhi . hingga jumlah minimal sampel terpenuhi. Jumlah sampel pada penelitian ini adalah 15 orang. Hasil penelitian yang dilakukan menunjukkan bahwa terdapat perbedaan tingkat nyeri sebelum dan sesudah diberikan guided imagery musik. Hal ini dapat dilihat bahwa sebelum diberikan intervensi guided imagery musik yang pada pasien pasca bedah pada pengukuran awal pada kelompok intervensi didapatkan rata-rata nyeri 5,17 sedangkan pengukuran ke dua menurun mnjadi rata-rata 3,1. Sedangkan pada kelompok kntol didaptakan hasil pengukuran awal rata-rata nyeri 5,11 dan pada pengukuran ke dua didapatkan hasil rata-rata nyeri 4,9 dan 5,0 pada pengukuran ke tiga. Hasil uji statistic pada penelitian ini ( $p$ value <0,05 baik evaluasi pertama maupun evaluasi efek retensi (satu jam setelah post test) atau pengukuran ke dua menunjukkan adanya penurunan nyeri yang bermakna antara sebelum dan sesudah dilakukan teknik guided imagery music pada pasien pasca bedah. Dapat disimpulkan Terdapat pengaruh yang signifikan intervensi Guided Imagery Music terhadap nyeri pada pasien Pasca bedah laparotomy. Disarankan hasil penelitian ini dapat memberikan masukan pentingnya intervensi mandiri yang dilakukan dalam menurunkan gejala gangguan fisiologis dan psikologis pada pasien-pasien pasca bedah seperti masalah nyeri, cemas dan perubahan tanda-tanda vital. Dalam meningkatkan kualitas pelayanan keperawatan diharapkan pemberian terapi guided imagery music dapat dijadikan protap dalam mengurangi nyeri dan perunbahan tanda-tanda vital pada pasien pasca pembedahan.
\end{abstract}

Kata Kunci: Nyeri, Laparatomi, penggunaan audio recorder guided imagery music (gim)

\section{ABSTRACK}

This study aims to determine the effectiveness of the use of guided imagery music (gim) audio recorders on pain in patients after laparotomy surgery at a hospital in front of Dr. Aloe Saboe, Gorontalo. This type of research is quasi-experimental with the design of "group pre and post test design with control group" pain measurements performed before and after the intervention. The population in this study were all patients after laparotomy surgery in the Surgery room at RSAS hospital. Sampling here is done by using Non Probobality Sampling with purposive sampling technique. The researcher took all subjects according to inclusion criteria until the minimum number of subjects was fulfilled. until the minimum number of samples is met. The number of samples in this study were 15 people. The results of the research showed that there were differences in the level of pain before and after being given guided imagery music. It can be seen that before being given intervention guided imagery music which in post-surgical patients at initial measurement in the intervention group obtained an average of 5.17 pain while the second measurement decreased to an average of 3.1. Whereas in the 
kntol group there was an average initial measurement of pain of 5.11 and at the second measurement, the average pain was 4.9 and 5.0 at the third measurement. Statistical test results in this study ( $p$ value $<0.05$ both the first evaluation and evaluation of the effect of retention (one hour after post test) or the second measurement showed a significant reduction in pain between before and after the guided imagery music technique was performed in postoperative patients. It can be concluded that there is a significant influence of Guided Imagery Music intervention on pain in patients. Post laparotomy surgery, it is suggested that the results of this study can provide input to the importance of independent interventions in reducing physiological and psychological symptoms in postoperative patients such as pain, anxiety and changes in vital signs In improving the quality of nursing services it is expected that the provision of guided imagery music therapy can be used as a protap in reducing pain and the development of vital signs in post-surgical patients.

Keywords: Pain, Laparatomy, use of audio imagery guided imagery music (gim)

\section{PENDAHULUAN}

Nyeri setelah pembedahan merupakan hal yang fisiologis, tetapi hal ini merupakan salah satu keluhan yang paling ditakuti oleh klien setelah pembedahan. Adapun bentuk nyeri yang dialami oleh klien pasca pembedahan laparatomi adalah nyeri akut yang terjadi karena adanya luka insisi bekas pembedahan. Menurut Nugroho (2011) pasien laparatomi $60 \%$ menderita nyeri yang hebat, $25 \%$ nyeri sedang dan $15 \%$ nyeri ringan. Sementara itu Megawati (2010), mengatakan bahwa pasien pasca laparatomi mengeluhkan nyeri sedang sebanyak $57,70 \%$, yang mengeluhkan nyeri berat $15,38 \%$, dan nyeri ringan sebanyak $26,92 \%$.

Nyeri akut yang dirasakan oleh klien pasca operasi merupakan penyebab stress, frustasi dan gelisah yang menyebabkan klien mengalami gangguan tidur, cemas, tidak nafsu makan, dan ekspresi tegang. Selain merasakan ketidak nyamanan nyeri juga mempengaruhi system pulmonal, kardiovascular, gastrointestinal, endokrin dan imonologi. Lebih rinci dalam Poter (2006) membagi respon nyeri terbagi dua yaitu respon physicilogis (perasaan tidak nyaman, cemas) dan fisiologis (peningkatan frekuensi napas, penigkatan tekanan darah dan denyut jantung hingga mual dan muntah).

WHO (2009) Jumlah tindakan pembedahan di dunia sangat besar, dari hasil penelitian di 56 Negara pada tahun 2004 diperkirakan jumlah tindakan pembedahan sekitar 234 juta per tahun, hampir dua kali lipat melebihi angka kelahiran per tahun termasuk pembedahan laparatomi, angka kejadian luka setiap tahun semakin meningkat, baik luka akut maupun luka kronis. Sebuah penelitian terbaru di Amerika menunjukkan prevalensi pasien dengan luka adalah 3.50 per 1000 populasi penduduk. Mayoritas luka pada penduduk dunia adalah luka karena pembedahan/trauma (48.00\%), sedangkan di Indonesia didapatkan data laporan Depkes RI (2007) menyatakan laparatomi meningkat dari 162 pada tahun 2005 menjadi 983 kasus pada tahun 2006 dan 1.281 kasus padatahun 2007. ${ }^{7} \mathrm{Di}$ Rumah sakit Prof DR Dr Aloe Saboe Kota Gorontalo didapatkan sesuai data medical record 3 bulan terakhir (s/dDesember 2016), pasien laparatomi berjumlah 42 orang.

Salah satu bentuk kegiatan non farmakologi untuk mengurangi Nyeri adalah Guided imagery adalah teknik relaksasi dengan menggunakan imajinasi seseorang dengan suatu cara yang dirancang secara khusus untuk mencapai efek tertentu. ${ }^{9}$ Teknik ini melibatkan konsentrasi pada relaksasi fisik. Saat pikiran rilex, maka fisik juga menjadi rilex, dengan menciptakan bayangan yang menyenangkan sehingga mengurangi keparahan nyeri. Dengan menggunakan bayangan yang hidup akan membantu kontrol nyeri lebih efektif. ${ }^{8}$ Pada teknik ini menstimulasi otak melalui imajinasi dapat menimbulkan pengaruh langsung pada sistem syaraf, endokrin, neuromodulator, endorfin dengan cara penghambatan impuls nyeri sehingga terjadi mekanisme pemutusan transmisi nyeri, sehingga nyeri yang dirasakan akan berkurang ataupun hilang. ${ }^{4}$ Sedangkan musik adalah sebuah kesatuan irama yang mempengaruhi fisiologis, psikologis manusia.

(Marion 2002) pengaruh musik relaksasi terhadap nyeri setelah bedah ginekologi dengan hasil terapi music efektif terhadap penurunan nyeri dengan $(p=0,01)$. Pada tahun 2010 musicolog Eric Cristencen menyimpulkan bahwa GIM cocok digunakan untuk pelayanan kesehatan baik di klinik maupun dirumah. ${ }^{13}$ Mc Kinney (1997), efek GIM terhadap suasana hati dan kortisol, dengan menyimpulkan bahwa GIM positif dapat mempengaruhi suasana hati dan 
mengurangi kadar kortisol. ${ }^{14}$ Sementara itu pada riset keduanya adalah Effek GIM terhadap pelepasan Endorphin dengan hasil menunjukkan bahwa GIM dapat menstimulus kadar endorphin perifer. Guided imagery perlu dikombinasi dengan musik dalam penatalaksanaan nyeri dengan sebuah metode (GIM) Guided imageri dan music dengan menggunakan teknologi audio recorder. Metode ini memiliki beberapa keuntungan dibanding dengan metode-metode komplementer lainya antara lain : GIM efektif waktu, efektif biaya, efektif pelaksanaan. GIM belum diaplikasikan untuk menurunkan nyeri pasca bedah selama pasien dirawat di RS. Oleh karena itu tertarik melakukan penelitian efektifitas GIM terhadap nyeri pada pasien pasca bedah Mayor Laparatomi di Rumah sakit Umum Prof DR Dr H Aloe Saboe Kota Gorontalo.

\section{METODA PENELITIAN}

Jenis penelitian ini adalah quasi experimen dengan desain "group pre and post test design with control group" pengukuran nyeri dilakukan sebelum dan sesudah intervensi. Populasi pada penelitian ini adalah semua pasien pasca bedah laparatomi di ruangan Bedah di rumah sakit RSAS. Pengambilan sampel disini dilakukan dengan cara Non Probobality Sampling dengan teknik Purposif sampling. Peneliti mengambil semua subjek sesuai criteria inklusi sampai jumlah subjek minimal terpenuhi . hingga jumlah minimal sampel terpenuhi. Jumlah sampel pada penelitian ini adalah 15 orang.

\section{HASIL}

\section{Karakteristik Responden}

Penelitian dilakukan terhadap 30 responden yang menjalani perawatan pasca operasi laparatomi hari ke 0 di Prof. Dr. H. Aloei Saboe Kota Gorontalo. Responden dibagi dalam dua kelompok yang mendapatkan intervensi Audio recorder Guided imagery music dan kelompok control dengan perlakuan standar. Besar sampel masing-masing 15 responden intervensi dan 15 responden kelompok kontrol.

Tabel 2.1

Distribusi Frekuensi Karakteristik Responden pada kelompok intervensi dan kelompok Kontrol

Tabel 2.2

Gambaran nyeri pada pasien pasca bedah.

\begin{tabular}{lccccc}
\hline \hline Karakterist & \multicolumn{5}{c}{ Pengukuran } \\
\cline { 2 - 6 } $\begin{array}{c}\text { ik } \\
\text { Kelompok }\end{array}$ & 1 & 2 & 3 & 4 & 5 \\
\hline Intervensi & 1.88 & 1.76 & 3.24 & 4. & 1. \\
& & & & 0 & 1 \\
Control & 2.0 & 1.8 & 2.9 & 4.9 & 3.4 \\
& 4 & 2 & 4 & & \\
\hline
\end{tabular}

Diagram 2.2

Gambaran Rata-rata nyeri pada pasien pasca bedah. 


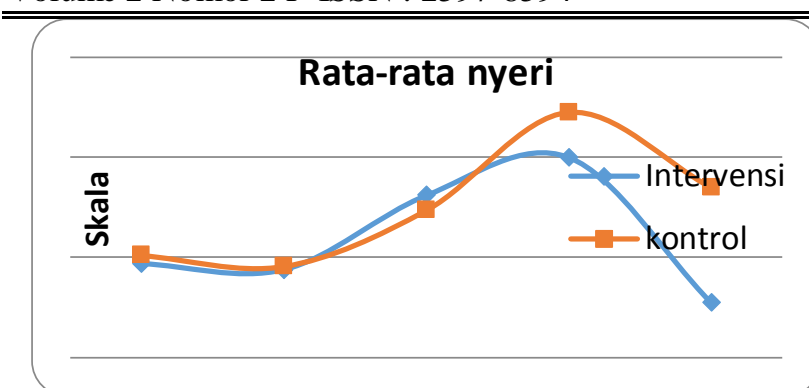

Berdasarkan Diagram 2.2 menunjukkan bahwa rata-rata nyeri terjadi peningkatan nyeri pada pengukuran ke 3 baik kelompok intervensi maupun control. Dan pada kelompok control pada garis merah terjadi peningkatan, dikarenakan oleh jumlah responden yang bertahan hingga pada jam ke 4 masih banyak berbanding terbalik dengan kelompok intervensi pada garis biru. Penurunan terjadi pada observasi ke 5 atau pada evaluasi pada post 2 baik pada kelompok intervensi dan control dikarenakan evaluasi sebagian pada pengukuran ke 4.

Tabel 2.3

Gambaran kategori nyeri Pada kelompok intervensi dan

Kelompok Kontrol. sedang menjadi 16 (94\%) dan nyeri berat sebesar $1(5.8 \%)$.

Tabel 2.4

Perbedaan Nyeri kelompok Intervensi dan contro

\begin{tabular}{l|c|c|c}
\multicolumn{4}{c|}{$\mathbf{l}$} \\
\hline \multicolumn{1}{c|}{ Kelompok } & $\mathrm{df}$ & $X^{2}$ & $\mathrm{p}$ \\
\hline Intervensi & 2 & 31,11 & 0,000 \\
\hline Kontrol & 2 & 5,04 & 0,600 \\
\hline
\end{tabular}

\section{Friedman Test}

Berdasarkan Tabel 2.4 hasil analisis dengan Uji Fried man pada kelompok intervensi menunjukkan nilai $p=0,000$ sehingga disimpulkan bahwa terdapat perbedaan tingkat nyeri yang bermakna pada kelompok intervensi, sedangkapn pada kelompok control menunjukan nilai $p=0,600$ sehingga disimpulkan tidak ada perbedaan tingkat nyeri pada kelompok control.

Tabel 2.5

Perbedaan tingkat nyeri pada masing-masing kelompok Intervensi dan pada kelompok control

\begin{tabular}{|c|c|c|c|c|c|c|c|c|c|}
\hline & & & & & & & & & \\
\hline & & & & & & & & & \\
\hline Kelompok & & & & & & Pindalpost1 & 8,50 & $-3,602^{\mathrm{a}}$ & 0,000 \\
\hline & & ngan & & dang & Berat & terRontrBbst2 & 9,00 & $-3,671^{a}$ & 0,000 \\
\hline Intervensi & $\mathbf{F}$ & $\%$ & $\mathbf{f}$ & $\%$ & f $\%$ & f Post\% & 6,00 & $-3,207^{a}$ & 0,001 \\
\hline Pre & - & & 17 & $100 \%$ & & - ppost2 & & & \\
\hline Post 1 & 13 & $76 \%$ & 4 & $41 \%$ & - & - Kontrol & & & \\
\hline Post 2 & 17 & $88.2 \%$ & 0 & $11 . \%$ & - & Pre-Post1 & 6,38 & -.998 & 0.323 \\
\hline Kontrol & & & & & & Pre - Post2 & 6,33 & -.456 & 0.642 \\
\hline Pre & 1 & $5.8 \%$ & 16 & $94 \%$ & & Post1-post2 & 6,80 & -.368 & 0.713 \\
\hline
\end{tabular}

Pre

$\begin{array}{llll}\text { Post } 1 & - & 16 & 94 \%\end{array}$

Post 2 $\begin{array}{llll}15 \quad 94 \% & 1 & 5.8 \%\end{array}$

Wilcoxon Signed Ranks Test

Berdasarkan Tabel 2.5 menunjukkan - bawa pada kelompok itervensi didapatkan hasil pre-post1 dengan MR 8,50 dengan nilai $\mathrm{p} 0,000$ yang berarti ada perbedaan antara pre dan post 1 . Sedangkan pada kelompok control pre-post1 didapatkan hasil $p=0,323$ sehingga disimpulkan tidak ada perbedaan tingkat nyeri pre ke post 1 .

Tabel 2.6 kat nyeri pada post ke 1 cenderung terjadi penurunan nyeri dengan hasil nyeri ringan 13 (76 $\%$ ), nyeri sedang 4 responden $(24 \%)$ dan nyeri berat $0 \%$. Seangkan pada kelompok control tingkat nyeri pada pre didapatkan nyeri ringan 1 $(5,8 \%)$, nyeri sedang sebesar $16 \quad(94 \%)$ Sedangkan tingkat nyeri pada post ke 2 nyeri

Berdasarkan Tabel 2.3 menunjukkan bawa hasil analisis univariat tingkat Nyeri pada kelompok intervensi Guided imagery music didapatkan pre : nyeri ringan $(0 \%)$ sedangkan nyeri sedang sebesar $17(100 \%)$. Sedangkan .

\begin{tabular}{l|c|c|c}
\hline \multicolumn{1}{c|}{ Kelompok } & Pre & Pos 1 & Pos 2 \\
\hline Intervensi & 5.17 & 3.1 & 2.4 \\
\hline Kontrol & 5.11 & 4.9 & 5.0 \\
\hline
\end{tabular}


Berdasarkan Tabel 2.6 menunjukkan ratarata nyeripada kelompok intervensi cenderung mengalami penurunan, sedangkan pada kelompok control terjadi fluktuasi nyeri.

Diagram 2.4

Gambaran Nyeri Sebelum dan Sesudah diberikan Intervensi Gim pada kelompok intervensi dan control

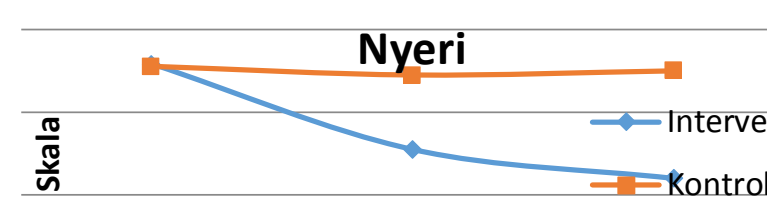

Berdasarkan Grafik 2.4 menunjukkan bahwa penurunan skor Nyeri dapat dilihat secara jelas, pada garis biru memperlihatkan skor Nyeri terjadi tren penurunan dan garis merah memperlihatkan skor nyeri pada kelompok control dengan hasil nyeri berfluktuasi. Pada garis biru dan merah tampak terpaut jauh.

Tabel 4.7

Perbedaan Tingkat Nyeri pada kelompok Intervensi dan kelompok kontrol pada pasien pasca bedah Laparatomi di BLUD RS Prof DR, Dr H Aloe saboe Kota

\begin{tabular}{lccc}
\hline Variabel & $\begin{array}{c}\text { Kelompok } \\
\text { Intervensi }\end{array}$ & $\begin{array}{c}\text { Kelompok } \\
\text { Kontrol }\end{array}$ & $\begin{array}{c}\boldsymbol{p} \text { - } \\
\text { value }\end{array}$ \\
\cline { 2 - 3 } & MR & MR & \\
\hline Pre & 17,68 & 17,32 & 0.919 \\
Post1 & 9.71 & 25,29 & 0.000 \\
Post 2 & 9,24 & 25,76 & 0.000 \\
\hline
\end{tabular}

Mann-Whitney Test

Berdasarkan tabel 4.8 menunjukkan bahwa hasil uji beda kelompok berpasangan antara kelompok sebelum dan sesudah perlakuan GIM didapatkan nilai $p=0.919$ artinya tidak ada perbedaan yang bermakna tingkat nyeri pre pada kelompok intervensi dan control. Hasil uji beda kelompok tidak berpasangan post ke 1 intervensi dan control memiliki nilai $p=0.000$ artinya ada perbedaan yang bermakna tingkat nyeri post ke 1 pada kelompok intervensi dan control. Sedangkan hasil uji beda post ke 2 pada kelompok tidak berpasangan antara intervensi dan kontrol didapatkan nilai $p=0.000$ artinya ada perbedaan yang bermakna tingkat nyeri pada kelompok intervensi dan kontrol.

\section{PEMBAHASAN}

\section{Jenis Kelamin}

Responden dalam penelitian ini mayoritas laki-lakis ebanyak 70,6\% sedangkan perempuan sebanyak 29,4\%. Temuan ini sejalan dengan karakteristik penelitian Haryati (2013) bahwa jenis kelamin pada pasien pasca bedah abdomen yang dirawat di rumah sakit laki-laki sebanyak 57,2 \% sedangkan perempuan sebanyak 42,8\%. ${ }^{33}$ Pada penelitian Stania dan Franly (2014) juga menyebutkan responden terbanyak adalah lakilaki sebesar $70 \%$.

Dapat disimpulkan bahwa jumlah pasien lakilaki lebih banyak daripadaperempuan yang menjalani bedah abdomen,hal ini sesuai dengan karakteristik laki-laki yang cenderung memiliki kebiasaan kurang baik disbanding perempuan. Hal ini dibuktikan dengan hasil Penelitian epidemiologi yang menunjukkan peranan kebiasaan mengkonsumsi makanan rendah serat dan pengaruh konstipasi terhadap timbulnya penyakit pada saluran pencernaan. Tinja yang keras dapat menyebabkan terjadinya konstipasi. Kemudian konstipasi akan menyebabkan meningkatnya tekanan intra sekal yang berakibat timbulnya sumbatan fungsional pada usus maupun kolonsehingga mengakibatkan meningkatnya pertumbuhan kuman micobakteri di usus atau kolon. Semua ini akan mempermudah timbulnya penyakit-penyakit pada saluran pencernaan yang beresiko untuk dilakukan pembedahan pada abdomen.

\section{A. Efektifitas Audio Recorder Guided Imagery music Terhadap Nyeri pada Pasien Pasca Bedah Laparatomi}

1. Guided imagery music terhadap Nyeri Hasil penelitian yang dilakukan menunjukkan bahwa terdapat perbedaan tingkat nyeri sebelum dan sesudah diberikan guided imagery musik. Hal ini dapat dilihat pada tabel bahwa sebelum diberikan intervensi guided imagery musik yang pada pasien pasca bedah pada pengukuran awal pada kelompok intervensi didapatkan rata-rata nyeri 5,17 sedangkan pengukuran ke dua menurun mnjadi rata-rata 3,1. Sedangkan pada kelompok kntol didaptakan hasil pengukuran awal rata-rata nyeri 5,11 dan pada pengukuran ke dua didapatkan hasil rata-rata nyeri 
4,9 dan 5,0 pada pengukuran ke tiga. Hasil uji statistic pada penelitian ini ( $p$ value $<0,05$ baik evaluasi pertama maupun evaluasi efek retensi (satu jam setelah post test) atau pengukuran ke dua menunjukkan adanya penurunan nyeri yang bermakna antara sebelum dan sesudah dilakukan teknik guided imagery music pada pasien pasca bedah.

Menurut melzeck dan well (1991), penggunaan metode psikologis untuk melawan nyeri menunjukan signifikan kontribusi terhadap nyeri.

Menurut Torrance \& Serginson (2010), ada tiga jenis sel saraf dalam proses penghantaran nyeri yaitu sel syaraf aferen atau neuron sensori, serabut konektor atau interneuron dan sel saraf eferen atau neuron motorik. Sel-sel syaraf ini mempunyai reseptor pada ujungnya yang menyebabkan impuls nyeri dihantarkan ke sumsum tulang belakang dan otak. Reseptorreseptor ini sangat khusus dan memulai impuls yang merespon perubahan fisik dan kimia tubuh. Berespon terhadap stimulus nyeri disebut nosiseptor. Stimulus pada jaringan akan merangsang nosiseptor melepaskan zat-zat kimia, yang terdiri dari prostaglandin, histamin, bradikinin, leukotrien, substansi $\mathrm{p}$, dan enzim proteolitik. Zat-zat kimia ini akan mensensitasi ujung syaraf dan menyampaikan impuls ke otak.

Menurut Smeltzer \& Bare (2009) kornu dorsalis dari medula spinalis dapat dianggap sebagai tempat memproses sensori. Serabut perifer berakhir disini dan serabut traktus sensori asenden berawal disini. Juga terdapat interkoneksi antara sistem neural desenden dan traktus sensori asenden. Traktus asenden berakhir pada otak bagian bawah dan bagian tengah dan impulsimpuls dipancarkan ke korteks serebri. Agar nyeri dapat diserap secara sadar, neuron pada sistem asenden harus diaktifkan. Aktivasi terjadi sebagai akibat input dari reseptor nyeri yang terletak dalam kulit dan organ internal.

Terdapat interkoneksi neuron dalam kornu dorsalis yang ketika diaktifkan, menghambat atau memutuskan taransmisi informasi yang menyakitkan atau yang menstimulasi nyeri dalam jaras asenden. Seringkali area ini disebut "gerbang". Kecendrungan alamiah gerbang adalah membiarkan semua input yang menyakitkan dari perifer untuk mengaktifkan jaras asenden dan mengaktifkan nyeri. Namun demikian, jika kecendrungan ini berlalu tanpa perlawanan, akibatnya sistem yang ada akan menutup gerbang.
Stimulasi dari neuron inhibitor sistem asenden menutup gerbang untuk input nyeri dan mencegah transmisi sensasi nyeri.

Pada teori yang kedua yaitu dapat menggunakan neuromodulator nyeri sebagai neurotransmitter yang bekerja sebagai penghambat nyeri yang dikenal dengan hormone endorphin. Pada saat neuron nyeri perifer mengirim sinaps, terjadi sinapsis antara neuron nyeri ferifer dan neuron yang menuju otak tempat seharusnya substansi $\mathrm{P}$ akan menghantarkan impuls sebagai neurotransmitter. Pada saat itu, tubuh menerima reaksi dari luar yang menghasilkan pengeluaran hormone endorphin, sehingga memblokir lepasnya substansi $\mathrm{P}$ dari neuron sehinggga signal nyerinya terputus.

Sementara itu pada riset Erick, (2010) adalah Effek GIM terhadap pelepasan Endorphin dengan hasil menunjukkan bahwa GIM dapat menstimulus kadar endorphin perifer. ${ }^{16}$ Guided imagery merupakan kegiatan klien membuat suatu bayangan yang menyenangkan, dan mengonsentrasikan diri pada bayangan tersebut serta berangsur-angsur membebaskan diri dari perhatian terhadap nyeri. ${ }^{8}$ Terapi ini dapat menurunkan nyeri karena didalamnya terdapat unsur terapi yang berfungsi untuk relaksasi atau untuk tujuan proses penyembuhan. Melalui guided imagery pasien akan terbantu untuk mengalihkan perhatian dari nyeri yang dirasakan dengan membayangkan hal-hal yang menyenangkan. Hal ini sehingga secara bertahap dapat menurunkan persepsi klien terhadap nyeri yang dirasakan.

Pemberian guided imagery merupakan salah satu upaya yang dilakukan untuk penanganan rasa nyeri yang dirasakan pasien. Terapi ini meningkatkan relaksasi pada pasien, mengalihkan konsentrasi dan perhatian dari rasa nyeri serta berangsur-angsur menurunkan persepsi terhadap rasa yang dirasakan.

Hasil penelitian Ratnasari, dkk (2013) pengaruh guided imagery terhadap nyeri pada pasien pasca operasi dengan hasil pada kelompok eksperimen didapatkan nilai t hitung sebesar 7,828 dengan nilai $\mathrm{p}$ value sebesar $0,000(\mathrm{p}<0,05)$. Sehingga dapat disimpulkan bahwa pemberian guided imagery signifikan terhadap nyeri.

Pada penelitian lainnya Yang Liu dkk, (2015) pengaruh terapi musik pada nyeri, kecemasan, dan tanda-tanda vital pada pasien pasca bedah toraks dengan hasil menunjukan nilai $\mathrm{p}=0,000<\alpha(0,05)$ hal ini berarti ada pengaruh yang signifikan musik terhadap nyeri. 


\section{KESIMPULAN}

Berdasarkan hasil penelitian mengenai "Efektivitas Audio Recorder Guided Imagery Music terhadap nyeri pada pasien Pasca bedah laparatomy di ruang ICU BLUD RS Prof DR dr H Aloe Saboe Kota Gorontalo musik dapat di simpulkan, sebagai berikut :

1. Rata-rata responden pasca bedah laparatomy mengalami nyeri sedang baik pada kelompok intervensi maupun kelompok control.

2. Terjadi penurunan nyeri secara signifikan pada kelompok intervensi setelah diberikan Guided imagery music, dan pada kelompok control tidak mengalami penurunan nyeri yang signifikan.

3. Terdapat pengaruh yang signifikan intervensi Guided Imagery Music terhadap nyeri pada pasien Pasca bedah laparatomy

Disarankan hasil penelitian ini dapat memberikan masukan pentingnya intervensi mandiri yang dilakukan dalam menurunkan gejala gangguan fisiologis dan psikologis pada pasienpasien pasca bedah seperti masalah nyeri, cemas dan perubahan tanda-tanda vital. Dalam meningkatkan kualitas pelayanan keperawatan diharapkan pemberian terapi guided imagery music dapat dijadikan protap dalam mengurangi nyeri dan perunbahan tanda-tanda vital pada pasien pasca pembedahan.

\section{DAFTAR PUSTAKA}

1. Potter and Patricia. Fundamental of nursing: concept, process dan practice. EGC. Jakarta. 2006.

2. Nugroho dan Taufan. Buku Ajar Obstetri untuk Mahasiswa Kebidanan. : Nuha Medika. Yogyakarta 2011

3. Permatasari. Hubungan pemberian lidokain intra vena terhadap perubahan laju jantung. jurnal medika muda. Kedokteran Undip. 2013

4. Potter. P A. dan Perry. Anne Griffin . Fundamental Keperawatan: Konsep, Proses dan Praktik. Alih bahasa: Yasmin Asih, dkk. Edisi 4. Vol 1.: EGC. Jakarta. 2005

5. Solehati. Konsep dan Aplikasi Dalam keperawatan Maternitas.aditama. Bandung. 2015

6. Brunner \& Sudart. Buku ajar keperawatan medical Bedah. EGC. Jakarta. 2001
7. Hendrik H. Penerapan Surgical Patient Safety Fase Time Out Pada Pasien Bedah Mayor Di IBS RSUD. Kebumen (2014).

8. Tamsuri. Nyeri Dan Penatalaksanaannya. EGC. Jakarta. 2010

9. Smeltzer, S C.. Buku Ajar Keperawatan Medikal Bedah Brunner \& Suddarth. Alih bahasa: Agung Waluyo, dkk. Ed. 8. Cetakan I. EGC. Jakarta. 2002

10. Marion. Relaksation and music reduce pain obstetry ginicology surgery. J. amerikan society of pain managemen. 2002 (in english)

11. Endarto. Perbedaan intensitas nyeri pada pasien cancer sebelum dan sesudah terapi music di RS Telogorejo Semarang. J. Ilmu Keperawtan 2012

12. Bonny, H. L. The Archives for Guided Imagery and Music. Journal Articles. 2012

13. Erick Cristencen. Guided Imageri With Music terapy A New GIM Program: present moments. 2012 (Tesis)

14. Bonny. Asosiation for music and terapy (AMI Method). 2010 (serial Online) URL : http//www.ami-method.htm diakses pada tanggal 20/4/2015

15. Mc kiney. Effets Of Guided Imagery and Music (GIM) Therapy on mood and cortisol in healthy adults. J. Music Terapy. 1997 (in engglish)

16. Endah Estria Nurhayati. Pengaruh teknik distraksi terhadap penurunan intensitas nyeri pada pasien laparatomi. Jurnal Ilmiah Keperawatan. 2011

17. Smeltzer and Suzana. Keperawatan Medical bedah Brunner and Sudart Ed. 8. EGC. Jakarta. 2001

18. Helms, J.E., \& Barone, C.P. Physiology and treatment of pain. Critical care nurse. 2008

19. Sjamsuhidrajat. Buku Ajar Ilmu Bedah.EGC.jakarta. 2005

20. Asmadi. Teknik Prosedural Keperawatan : Konsep dan Aplikasi Kebutuhan Dasar Klien. Jakarta : Salemba Medika. 2008

21. Baradero. Prinsip dan praktek keperawatan perioperatif. EGC.Jakarta. 2009

22. Marison. Manajemen Luka. EGC. Jakarta.2004

23. Kalbe Compani. Nonsteroid Anti inflamasi Agents (NSaids). Jakarta. 2015

24. http://www.hexpharmjaya.com/page/keto $\underline{\text { rolac.aspx }}$ 
Volume 2 Nomor 2 P-ISSN : 2597-8594

25. Purwanto. Herbal dan Keperawatan Komplementer. Nuha medika. Yogyakarta. 2013

26. Depkes. Permenkes. RI No. 1109/Menkes/Per/IX/2007/Penyelenggaran Pengobatan Komplementer di Fasilitas Kesehatan.jakarta. 2007

27. Guyton A. C., Hall J. E. . Buku Ajar Fisiologi Kedokteran. Edisi 9: EGC. Jakarta. 1997

28. AMI (Association for Music and Imagery, 2009) FREQUENTLY ASKED QUESTIONS ABOUT THE BONNY METHOD OF GUIDED IMAGERY AND MUSIC. Denmark. 2010

29. Mender. Nyeri persalinan. EGC. Jakarta. 2012 